\title{
The role of mood and message ambiguity in the interplay of heuristic and systematic processing
}

\author{
GERD BOHNER, SHELLY CHAIKEN and \\ PIROSKA HUNYADI \\ New York University
}

\begin{abstract}
The mechanisms by which mood states influence attitude judgments in persuasion settings are delineated in terms of current dual-process theorizing, with an emphasts on mechanisms that may operate when the evaluative implications of message content are ambiguous. In a preliminary test of hypotheses concerning such circumstances, college-aged subjects were put into a happy or sad mood and then read a message containing unamblguous strong, unambiguous weak, or ambiguous arguments, which was attributed to a highly credible source (heuristic cue) When message content was ambiguous, sad (as compared to happy) subjects' attitudes were more influenced by heurtstic processing. and their message-related thoughts were blased by the heuristic cue. These and other results are discussed within a dual-processing framework, and compared to other social cognition theorizing on the impact of affect on social Judgment.
\end{abstract}

\section{INTRODUCTION}

A considerable amount of recent research has drawn upon the heuristic-systematic model (HSM; Chaiken, 1980, 1987; Chaiken, Liberman and Eagly, 1989) and the elaboration likelihood model (ELM; Petty and Cacioppo, 1981, 1986) to investigate the impact of people's mood states on processing and attitude judgment (e.g. Bless, Bohner, Schwarz and Strack, 1990; Bless, Mackıe and Schwarz, 1992; Bohner, Crow, Erb and Schwarz, 1992; Innes and Ahrens, 1991, Mackie and Worth, 1989; Worth and Mackıe, 1987; for reviews, see Eagly and Chaiken, 1993; and Schwarz, Bless and Bohner, 1991). This paper extends previous work by contrastıng divergent predic-

The reported research was facilitated by a Feodor Lynen research fellowshıp from the Alexander von Humboldt foundation to G. Bohner; a Deutsche Forschungsgemeinschaft grant Schw 278/5 to N. Schwarz, H. Bless, and G. Bohner; and a National Institute of Mental Health grant MH43299 to S. Chaiken. A preliminary report was presented at the EAESP-SESP Joint Meeting, Leuven/Louvain-la-Neuve, Belgium, July 1992.

Correspondence should be addressed to Gerd Bohner, who is now at the Unıversity of Mannheim, Socral Psychology, D-68131 Mannheim, Germany or to Shelly Chaiken, Department of Psychology, New York University, 6 Washington Place, New York, NY 10003, U.S.A. 
tions, and by delineating the circumstances under which various mediators of mood effects on judgment may be most likely to operate.

\section{Processing persuasive communications}

The HSM and ELM distınguish two strategies of information processing in persuasion settings. Systematic processing, or central route persuasion (Petty and Cacioppo, 1981), entails thınkıng carefully about persuasıve arguments and other issue-related information. When such processing occurs, people typically are more persuaded by messages that contain strong rather than weak arguments. When systematic processing is minımal, persuasıon may still occur because people utilize simple heuristics based on salient non-content cues such as communicator expertise or other people's opinıons. When such heuristic processing, or peripheral route persuasion (Petty and Cacioppo, 1981), predominates, argument quality typically exerts little persuasive impact (see Eagly and Chaiken, 1993)'.

Because systematic (central) processing is presumed to be more effortful and capacity-constrained than heuristic (peripheral) processing, it requires both motivation and ability When either factor is low, heuristic processing is the dominant mechanism by which people form attitude judgments. These assumptions (and several others) are common to the ELM and HSM, whereas others are unique to one or the other model (see Eagly and Chaiken, 1993).

A particularly important difference between these models concerns the relation between processing modes. The ELM's two routes are conceived as generally antagonistıc: factors that increase the likelihood of central route persuasion decrease the likelihood of peripheral route persuasion, and vice versa (e.g. Petty and Cacioppo, 1986, pp. 141-165). In contrast, the HSM assumes that heuristic and systematic processing can co-occur. As a consequence, they are assumed capable of exerting either additive or interactive effects on judgments, depending on a number of mutable factors (see Chaiken et al., 1989).

Of particular interest here is the interactive hypothesis that heuristic processing may bias systematic processing. Specifically, the HSM proposes that people's heuristic processing of cues such as source expertise or consensus information establish expectancies about the probable validity of a message (or the probable quality of an attitude object). These expectancies, in turn, are assumed capable of exerting a selective influence on people's perception and evaluation of persuasive argumentation. Importantly, this biasing effect of heuristic processing is assumed to occur mainly when motivation for systematic processing is high and when persuasıve argumentation is amenable to distorted interpretation, that 1s, when arguments are ambiguous (Chaiken et al., 1989; Chaiken and Maheswaran, in press).

\footnotetext{
'Differences between these models' definitions of peripheral versus heuristic processing should be noted. Within the ELM, any attitude change that is the effect of some non-content cue and is independent of argument quality is subsumed under the 'peripheral route' This definition encompasses a diversity of processes (see Petty and Cacioppo, 1986). The HSM's definition of heuristic processing is more specific. It requires that 'non-content' cues (e.g. number of arguments) activate associated cognitive heuristics (e.g. 'length implies strength'), and that attıtude judgments are based on the evaluative implicatıons of these heuristics (see Chaiken et al., 1989).
} 


\section{The impact of affective states}

Dual-process theorizing suggests several ways in which mood may influence persuasion (see Eagly and Chaiken, 1993; Petty, Cacioppo and Kasmer, 1988; Schwarz et al., 1991). Yet the majority of existing findings point to one main mechanism: amount of systematic processing. Specifically, positive affect during message exposure decreases systematic processing, as compared to negative or neutral affect. Hence, elated subjects are typically less persuaded by strong arguments, but more persuaded by weak arguments, than subjects who are in either mildly negative or neutral moods (e.g. Bless et al., 1990, 1992; Bohner et al., 1992; Innes and Ahrens, 1991, Worth and Mackie, 1987).

Although mood-related decrements in capacity for systematic processing have been suggested to explain these findings (e.g. Mackie and Worth, 1989), the more likely explanation in our view is mood-induced differences in motivation for processing (see Bohner et al., 1992; Schwarz et al., 1991). According to this account, sad mood signals potential threat and thus leads to detail-oriented, analytic processing aimed at regaining control or dealing with a potentially problematic situation. By contrast, happy mood informs the person that the current situation is unproblematic, thus obviating the need for effortful cognitive processing and fostering simple, heuristic strategies (Fiedler, 1988; Frijda, 1988; Isen, 1987; Schwarz, 1990; Schwarz et al., 1991).

\section{Alternative mechanisms underlying the mood-persuasion relation}

It is noteworthy that recent mood studies have not typically observed mood main effects on persuasion. This fact has cast doubt on two additional mediational possibilities, that mood may influence persuasion relatively directly, through some heuristic or peripheral mechanism, and that mood may influence persuasion indirectly, through mood-congruent systematic processing (see Schwarz et al., 1991). Recently, however, Petty, Schumann, Richman and Strathman (1993) reported findings consistent with both possibilitıes. When motivation for processing was relatively low, mood appeared to exert a direct effect on judgment, with positive mood leading to more persuasion than neutral mood. When motivation for processing was higher, however, subjects' mood influenced attitudes indirectly via the favourability of the thoughts they generated in response to the message. According to these researchers' ELM-based multiplerole analysts of affect (Petty et al., 1988), under conditions of low motivation (or ability) for processing, recipients may (mis)interpret their mood as a reaction to the message, and use it as a basis for judgment according to a 'how do I feel about it?' heuristic (Schwarz, 1990). Yet under conditions of high motivation, positive mood is assumed to facilitate the recall of positive material in memory (e.g. Bower, 1981), and thus facilitate positive elaborations of message content. In other words, high 'elaboration' conditions are held to foster mood-congruent systematic processing or, in ELM terminology, biased central route persuasion.

Note that the latter, mood-congruent processing prediction can also be explained in terms of the HSM's bias hypothesis: if mood can function as an heunstic cue, as Schwarz et al. (1991) proposed, it has the potential to bias systematic processing - if message content is relatively ambiguous. In this regard, it is possible that the moderately strong and weak messages used by Petty et al. (1993) were more ambıguous 
than those used in previous studies (although Petty et al. did not explicitly construct their messages to be ambiguous).

According to the HSM conception of systematic processing, people in sad moods should 'access and scrutinize all [italics added] informational input for its relevance and importance to their judgment task, and integrate all useful information [italics added] in forming their judgments' (Chaiken et al., 1989, p. 212). If message content is sufficiently detailed and has clear-cut evaluative implications, sad persons' attitudes should be primarily mediated by message- (and issue-) related thınkıng, and the impact of heuristic cues should be hard to detect, due to attenuation (Chaiken et al., 1989).

If, however, argumentation is ambiguous or, perhaps, insufficient, sad persons' systematic processing may be biased by heuristic processing. Under these circumstances, sad subjects' attitudes would be mediated by message-related thinkıng. Yet the valence of this thought would be biased by these sad recipients' prior processing of heuristic cues such as source credibility or consensus information.

Happy persons generally lack motivation for systematıc processing. Their attıtudes should primarily be determined by heurstic processing, independent of the amount, strength, or ambiguity of persuasıve arguments. Indeed, in the absence of a judgmentoriented processing goal, they may even be less influenced by heuristic cues than sad recipients (see Chaiken et al.'s (1989) enhancement hypothesis).

Initial evidence for the co-occurrence of systematic and heuristic processing under sad mood was obtained by Bohner et al. (1992). In this study, happy and sad subjects were confronted with a request to donate money to a charity This request was insufficiently justified (i.e. only one strong or one weak argument was given), but was presented in combination with a salient strong or weak consensus cue (a list of contributors containing many versus few names). Happy subjects' responses to the request were uninfluenced by either the heuristic cue or the content of the message, whereas sad subjects' responses were influenced by both factors. Additional analyses (see Bohner, 1990) yielded findings consistent with the HSM's bias hypothesis: when the donation request was accompanied by a strong consensus cue, sad (but not happy) subjects tended to evaluate its content more positively than when it was paired with a weak cue.

\section{Mood and message ambiguity}

To further explore the interplay of heuristic and systematic processing under sad mood, we had happy or sad subjects read a message toutıng the attributes of a new telephone answering machine, the XT-100. This message contained extensive persuasive argumentation, but its ambiguity and strength was varied. In all conditions, a positive heuristic cue was provided.

We expected sad subjects to process more systematically than happy subjects, an effect that normally would produce an interaction between mood and argument quality. However, because a positive heuristic cue was available to all subjects (unlike most previous work), our predictions had to take this factor into account. We therefore expected sad (versus happy) subjects to report less favourable attitudes when exposed to weak arguments, because in this condition, sad subjects' systematic processing and happy subjects' heuristic processing should yield relatively negative and relatively positive evaluations of the $X T-100$, respectively. No mood difference in 
persuasion was expected for the strong argument condition, however; in this condition sad subjects' systematic processing and happy subjects' heuristic processing should both yield relatively favourable evaluations of the XT-100.

Two predictions were entertained for the ambiguous message conditions. According to the HSM's bias hypothesis, no mood difference in persuasion should obtain because sad subjects' systematic processing should be positıvely biased by the heuristic cue, leading them to form attitudes no less favourable than those formed by happy subjects (via heuristic processing alone). However, to the extent that (1) mood itself is used as an heuristic cue or (2) mood-congruent processing mediates attitudes, happy subjects would be expected to form more positive evaluations of the XT-100 than sad mood subjects.

Our predictions regarding the impact of mood on attitude judgment per se were tested by analysis of vanance (ANOVA) and appropriate contrasts, and our more specific hypotheses regarding the mediation of persuasion were tested by regression analyses.

\section{METHOD}

\section{Subjects and design}

One hundred and forty-nine introductory psychology students at New York University partıcipated in partial fulfilment of a course requirement. They were randomly assigned to conditions in the study's 3 (message content: ambiguous strong, ambiguous, unambiguous weak) $\times 2$ (mood: happy, sad) design. Data from 35 subjects were eliminated from the analyses, because they failed to follow instructions in the mood induction task $(N=7)$ or suspected a relationship between this task and the persuasive message $(N=28)$; discarded subjects were evenly distributed across conditıons, $\chi^{2}(5 ; N=149)=4.39, p>0.48$.

\section{Procedure}

Subjects participated in small group sessions in a room fitted with privacy panels. They were told that two different studies were being conducted, one on 'autobiographical memory' and one on 'product evaluation' The first of these allegedly unrelated studies manipulated and measured mood and the second presented and assessed the impact of the persuasive message. After completing an open-ended suspicion probe, subjects were debriefed.

\section{Independent variables}

\section{Mood}

Subjects were asked to recall and describe either a happy or a sad life event, ostensibly to and in the construction of an 'Autobiographical Memory Inventory' They were given 10 minutes to write down the event, and were encouraged to 're-live' the emotrons the event had elicited (cf Bless et al., 1990). 


\section{Message content}

In the 'product evaluation study', subjects learned that the manufacturer of a new telephone answering machine, the XT-100, was seeking the opinions of potential consumers. Subjects read a 'test report' which compared the XT- 100 to two competing brands on six attributes and asserted that the XT-100 was the best brand. Depending on message conditions, the XT-100 was described as superior on four important attributes and inferior on two unimportant ones (unambiguous strong), superior on four unimportant attributes and inferior on two important ones (unambiguous weak), or as superior/inferior on equal numbers of important/unimportant attributes (ambiguous: see Table 1) ${ }^{2}$.

Table 1. Attributes and valence of attribute-comparison (+ versus -) used to construct the unambiguous strong $(S)$, unambiguous weak $(W)$, and two ambiguous messages $\left(A_{1}, A_{2}\right)$

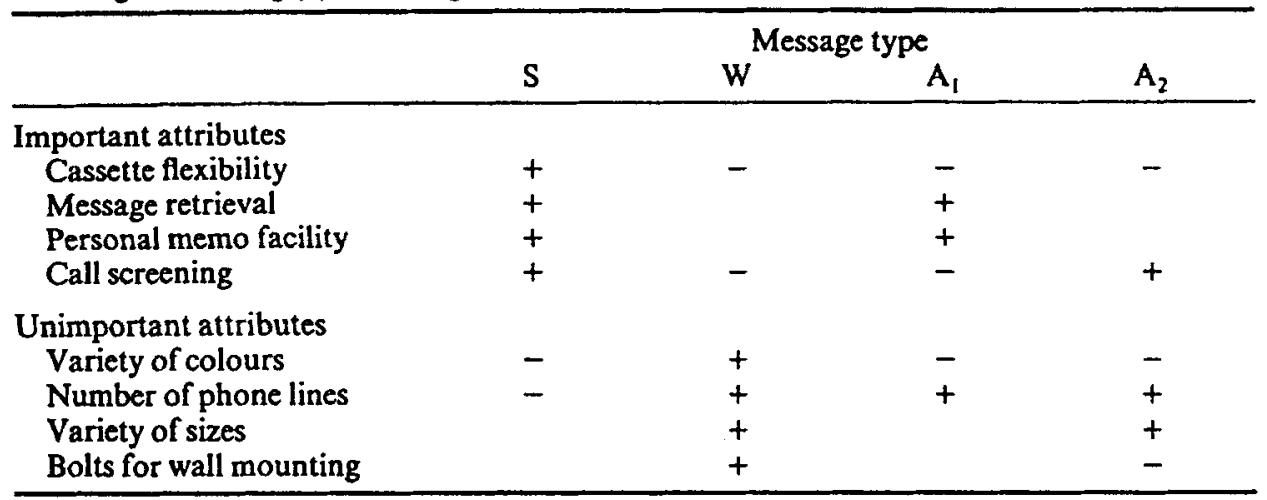

Entries indicate that an attribute was included in the message, and whether the target product was portrayed as supenor $(+)$ or inferior $(-)$ to its competitors on that attribute.

\section{Positive source cue}

Prior to reading the test report, all subjects learned that it had been excerpted from Consumer Reports, a magazine specializing in the scientific testing of consumer products. Prior research (Chaiken and Maheswaran, in press) indicated that subjects would regard this source as expert and trustworthy.

\section{Manipulation checks}

After the mood induction subjects rated how they felt 'right now at this moment' on a scale anchored by 'bad' (1) and 'good' (11). This question was embedded in a questionnaire that subjects believed was part of the autobiographical memory study.

After message exposure and the assessment of the dependent variables (see below),

\footnotetext{
${ }^{2}$ These materials were adapted from Chaiken and Maheswaran (in press). For methodological reasons two renditıons of the ambiguous message were used, with subjects randomly assigned to one or the other. As in the Chaiken and Maheswaran study, prelimınary analyses confirmed that the two renditions produced virtually identical findings. The reported analyses therefore feature only the theoretically important levels of the message content factor (strong versus ambiguous versus weak).
} 
subjects rated the extent to which the test report had portrayed the XT-100 as having few (versus many) positive features, many (versus few) negative features, fewer (versus more) positive features than other brands, more (versus fewer) negative features than other brands, and as inferior (versus superior) to other brands; responses to these $(-4$ to +4$)$ scales were averaged to form one message perception index (Cronbach's $a=0.85$ ).

Source evaluation ratings were collected to verify that the message source was perceived positively and also for use in the regression analyses. Subjects rated the credibility, reliability, trustworthıness, and expertıse of Consumer Reports on bıpolar $(-4$ to +4$)$ scales, and these responses were averaged to form one source evaluation index $(\alpha=0.95)$.

\section{Dependent variables}

\section{Attitudes}

Subjects rated the extent to which they would consider buying the XT-100, their favourability toward the XT-100, and the extent to which they regarded the product as useful and as good. Responses to these $(-4$ to +4$)$ scales were averaged to form one attitude index $(a=0.89)$.

\section{Cognitlve responses}

Subjects were given 3 minutes to list any thoughts they might have had while reading the test report. Two independent raters later categorized subjects' thoughts as attrbute-related or source-related $(A, S)$, and as favourable, unfavourable, or neutral toward the XT-100 $(+,-, n)$. Interrater agreement was 94 per cent and 84 per cent for the content and valence codings, respectively; disagreements were resolved by discussion.

Two indexes were created from data: valenced attribute-related thoughts (VAT) and valenced source-related thoughts (VST). Each was formed by subtracting the proportion of negative from the proportion of positive thoughts in the relevant category VAT indexed the valence of systematic processing, whereas VST (and the source evaluation index) indexed the valence of heuristic processing.

\section{RESULTS}

The hypotheses were tested by three-way mood $\times$ message content $\times$ gender ANOVAs and regression analyses.

\section{Manipulation checks}

The check on the mood induction yielded means of 8.21 and 4.75 for the happy and sad conditions, respectively, $F\left(1,101^{3}\right)=56.10, p<0.0001^{4}$ Percelved message

\footnotetext{
${ }^{3}$ One subject did not respond to the mood question.

4A mood $\times$ gender interaction, $p<0.03$, indicated that this effect was stronger for female subjects $\left(M_{\text {happy }}=8.96, M_{\text {sad }}=4.36\right)$ than for male subjects, $\left.M_{\text {happy }}=7.61, M_{\text {sad }}=5.14\right)$. However, simple effects tests confirmed that the induction was reliable for males $(p<0.001)$ as well as females $(p<0.001)$.
} 
content means for the strong, ambiguous, and weak messages were $+2.73,+1.78$, and +1.47 , respectively, $F(2,102)=7.72, p<0.002$. Finally, the grand-mean for the source evaluation index was +1.38 , which differed significantly from the scale midpoint $(0), F(1,100)=5777, p<0.001$. Thus the mood and message manipulatrons were successful and Consumer Reports was regarded as a credible source.

\section{Attitudes}

The ANOVA on postmessage attitudes yielded a main effect for argument strength, $F(2,102)=19.71, p<0.001$, with means of $+2.20,+1.31,+0.03$, for the unamb1guous strong, ambiguous, and unambiguous weak messages, respectively Although the mood $\times$ message interaction was not reliable, the means patterned in accord with our specific predictions. Recall that we expected a happy-sad difference to emerge only in the unambiguous weak message condition, where sad subjects' systematic processing of message content and happy subjects' heuristic processing of the source cue would produce divergent evaluations of the XT-100. Planned comparisons confirmed that given weak arguments, sad (versus happy) subjects indeed reported more negative attitudes $(M s=-0.34$ versus +0.42$), t(102)=1.69, p<0.05$, one-tailed. This happy-sad contrast was nonsignificant within the ambiguous $\left(M_{\text {happy }}\right.$ $\left.=+1.33 ; M_{\mathrm{sad}}=+1.29\right)$ and strong argument conditions $\left(M_{\mathrm{happy}}=+2.28 ; M_{\mathrm{sad}}\right.$ $=+2.13)$, each $t<1^{5}$

\section{Cognitive responses}

Overall, the valence of subjects' attribute-related thoughts was slightly negative (grand-mean $=0.12$ ). These VAT scores became more negative as message type changed from unambiguous strong to ambiguous to unambiguous weak $(M \mathrm{~s}=0.01$ versus -0.15 versus -0.22$), F(2,102)=7.98, p<0.002$. The only other effect to attain even margınal significance was a mood main effect, $F(1,102)=2.95, p<0.09$ Contrary to what might be expected if mood congruent systematic processing occurred, VAT scores were more negative among happy (versus sad) subjects $(M s=-0.17$ versus -0.07$)$.

Valenced source-related thinking was also slightly negative on an overall basis (grand-mean $=-0.02$ ). The ANOVA on these VST scores yielded only one reliable effect. Women's source-related thinkıng was more positive than men's, $F(1,102)=$ $6.05, p<0.02$.

\section{Regression analyses}

Hierarchical regression analyses tested our hypotheses regarding the mediation of persuasion. In the first set of analyses, the relative contributions of heuristic and systematic processing in the various experimental conditions were analysed. This was accomplished by regressing subjects' attıtudes on the experımental mood and message manipulations, valenced attribute-related thınkıng, valenced source-related

\footnotetext{
${ }^{3}$ In additıon, a marginal main effect of gender, $p<0.08$, and a marginal interaction of argument strength and gender emerged, $p<0.10$. These indicated that women (versus men) tended to report more positive attitudes, and were also slightly less influenced by the message manipulation. Neither of these trends, however, interacted with mood (all $p s>0.25$ ).
} 
thinking, and on cross-product terms which represent the theoretically meaningful interactions among these predictors (see Table 2).

In a second set of regressions, the HSM's bias hypothesis was tested: valenced attribute-related thoughts were regressed on the mood and message manipulations, source evaluations, and the interactions of these variables (see Table 3).

Finally, to explore mood-congruency effects, attitudes were regressed on the mood manıpulation-check scores, along with the experimental independent variables and interaction terms. Results of these three analyses are described in turn.

\section{Predicting attutudes from valenced thought measures}

With the attitude index as the dependent variable, we used the following predictor variables: message strength $(+1=$ strong; $0=$ ambiguous; $-1=$ weak), message ambiguity $\left(-1=\right.$ unambiguous; $+2=$ ambiguous $^{6}$, induced $\operatorname{mood}(0=\mathrm{sad}$; $1=$ happy), valenced source-related thoughts (VST, range -1 to +1 ), and valenced attribute-related thoughts (VAT, range -1 to +1 ). Both main effects and interaction terms were entered in the equation, as specified in panel (a) of Table 2 . In addition, separate regressions were performed for each mood condition to further diagnose potential interactions, as specified in panels (b) and (c) of Table 2.

These analyses generally confirmed predictions. Overall, VAT was positively related to attıtude judgments, semipartial $r=0.26, p<0.001$, indicating that systematic processing mediated attitude judgment. In line with previous research (Bless et al., 1990; Bohner et al, 1992), this relationship was somewhat stronger under sad $\left(r=0.35^{7}\right)$ than under happy mood $(r=0.21)$, although the VAT $\times$ mood interaction was unreliable, $r=-0.08$.

In addition, the significant negatıve coefficient for the VST $\times \operatorname{mood} \times$ ambiguity interaction $(r=-0.20, p<0.01)$ indicates that the contribution of source-related thinkıng covaried with specific combinations of mood and ambiguity Together with the significant simple interaction of VST by ambiguity under sad mood $(r=0.22$, $p<0.05$ ), this supports the hypothesis that the contribution of heuristic processing in predicting judgment increased when sad subjects received an ambiguous message. Happy subjects, by contrast, relied on the heuristic cue independent of message ambiguity, as indicated by the significant simple main effect of VST $(r=0.31, p<0.01$, sad mood: $r=-0.01$, n.s.) and the unreliable simple VST $\times$ ambiguity interaction $(r=-0.15, p>0.15)$.

These results indicate that, although sad and happy subjects' attitude judgments were mediated by systematic processing, sad subjects' attitudes depended somewhat more on this processing strategy Further, happy subjects' attitudes were generally influenced by source-related thoughts, whereas sad subjects' attitudes depended on source-related thoughts only when they received an ambiguous message. In this condition, then, heuristic and systematic processing co-occurred for sad subjects.

\footnotetext{
'Note that the contributions of message strength and ambiguity can be thought of statistıcally as orthogonal contrasts.

${ }^{7}$ This and all following $r$-statistics in this section denote semipartial correlation coeffictents.
} 
Table 2. Regression analysis predictung attutudes from valenced thought measures

\begin{tabular}{|c|c|c|c|}
\hline Step & Effect* & Beta & Semıpartıal $r$ \\
\hline \multicolumn{4}{|c|}{ (a) Full design } \\
\hline \multirow[t]{5}{*}{1} & Strength ( $1=$ strong, $0=$ ambiguous, $-1=$ weak $)$ & 0.40 & $0.37 \ddagger$ \\
\hline & Ambiguity $(-1=$ unamb., $+2=$ amb.) & 0.06 & $0.06^{\circ}$ \\
\hline & $\operatorname{Mood}(0=$ sad, $1=$ happy $)$ & 0.12 & 0.12 \\
\hline & Valenced Attribute-Related Thoughts (VAT) & 0.28 & $0.26 \ddagger$ \\
\hline & Valenced Source-Related Thoughts (VST) & 0.13 & $0.12^{\top}$ \\
\hline \multirow[t]{3}{*}{2} & Mood $\times$ strength & -0.14 & -0.10 \\
\hline & Mood $x$ ambiguity & -0.09 & -0.06 \\
\hline & VAT $\times$ VST & -0.22 & $-0.20 \S$ \\
\hline \multirow[t]{6}{*}{3} & VST $\times \operatorname{mood}$ & 0.12 & 0.08 \\
\hline & VST $\times$ strength & -0.06 & -0.06 \\
\hline & VST $\times$ ambiguity & 0.03 & 0.02 \\
\hline & VAT $\times$ mood & -0.16 & -0.08 \\
\hline & VAT $\times$ strength & -0.10 & -0.08 \\
\hline & VAT $\times$ ambiguity & 0.05 & 0.03 \\
\hline \multirow[t]{4}{*}{4} & VST $\times$ mood $\times$ strength & -0.07 & -0.05 \\
\hline & VAT $\times$ mood $\times$ strength & 0.24 & 0.07 \\
\hline & VST $\times$ mood $\times$ ambiguity & -0.49 & $-0.20 \S$ \\
\hline & VAT $\times$ mood $\times$ ambiguity & -0.16 & -0.07 \\
\hline \multicolumn{4}{|c|}{ (b) Happy mood conditions } \\
\hline \multirow[t]{4}{*}{1} & Strength $(1=$ strong, $0=$ ambiguous, $-1=$ weak) & 0.39 & $0.35 \S$ \\
\hline & Ambiguity $(-1=$ unamb., $+2=a m b)$. & 0.03 & 0.03 \\
\hline & VAT & 0.23 & 0.21 \\
\hline & VST & 0.31 & $0.31 \S$ \\
\hline 2 & VAT $\times$ VST & -0.11 & -0.08 \\
\hline \multirow[t]{4}{*}{3} & VST $\times$ strength & -0.20 & -0.18 \\
\hline & VAT $\times$ strength & -0.07 & -0.05 \\
\hline & VST $\times$ ambiguity & -0.17 & -0.15 \\
\hline & VAT $\times$ ambiguity & -0.08 & -0.06 \\
\hline \multicolumn{4}{|c|}{ (c) Sad mood conditıons } \\
\hline \multirow[t]{4}{*}{1} & Strength $(1=$ strong, $0=$ ambiguous, $-1=$ weak $)$ & 0.44 & $0.42 \ddagger$ \\
\hline & Ambiguity $(-1=$ unamb., $+2=a m b)$. & 0.13 & 0.12 \\
\hline & VAT & 0.36 & $0.35 \S$ \\
\hline & VST & -0.00 & -0.01 \\
\hline 2 & VAT $\times$ VST & -0.21 & -0.20 \\
\hline \multirow[t]{4}{*}{3} & VST $\times$ strength & -0.02 & -0.02 \\
\hline & VAT $\times$ strength & -0.19 & -0.11 \\
\hline & VST $\times$ ambiguity & 0.42 & $0.22 \S$ \\
\hline & VAT $\times$ ambiguity & 0.16 & 0.09 \\
\hline
\end{tabular}

* Each effect is adjusted for all effects entered in the same or preceding steps. $\dagger p<0.01 ; \ddagger p<0.05 ; \$ p<0.001$.

\section{Predicting attribute-related thoughts from source evaluations}

In the second set of regressions, shown in Table 3, we tested whether subjects' perceptions of the source biased their systematic processing. VAT scores were the criterion variable, and manıpulated mood, message strength and ambiguity, source evaluation, and their interactions served as predictors.

According to the HSM's bias hypothesis, valenced attribute-related thinking 
Table 3. Regression analysis predicting valenced attribute-related thoughts from source evaluations

\begin{tabular}{|c|c|c|c|}
\hline Step & Effect* & Beta & Semipartial $r$ \\
\hline \multicolumn{4}{|c|}{ (a) Full design } \\
\hline$i$ & $\begin{array}{l}\text { Strength }(1=\text { strong, } 0=\text { ambiguous, }-1=\text { weak }) \\
\text { Ambiguity }(-1=\text { unamb., }+2=\text { amb. }) \\
\text { Mood }(0=\text { sad, } 1=\text { happy) } \\
\text { Source evaluation (SE) }\end{array}$ & $\begin{array}{r}0.29 \\
-0.09 \\
-0.18 \\
0.20\end{array}$ & $\begin{array}{l}0.29 \dagger \\
-0.09 \\
-0.18 \ddagger \\
0.20 \ddagger\end{array}$ \\
\hline 2 & $\begin{array}{l}\text { Mood } \times \text { strength } \\
\text { Mood } \times \text { ambiguity }\end{array}$ & $\begin{array}{r}-0.23 \\
0.02\end{array}$ & $\begin{array}{r}-0.16 \\
0.01\end{array}$ \\
\hline 3 & $\begin{array}{l}\text { SE } \times \text { mood } \\
S E \times \text { strength } \\
S E \times \text { ambiguity }\end{array}$ & $\begin{array}{r}-0.49 \\
-0.31 \\
0.23\end{array}$ & $\begin{array}{r}-0.13 \\
-0.08 \\
0.06\end{array}$ \\
\hline 4 & $\begin{array}{l}\text { SE } \times \text { mood } \times \text { strength } \\
\text { SE } \times \text { mood } \times \text { ambiguity }\end{array}$ & $\begin{array}{l}-0.27 \\
-1.31\end{array}$ & $\begin{array}{l}-0.05 \\
-0.23 \dagger\end{array}$ \\
\hline \multicolumn{4}{|c|}{ (b) Happy mood conditions } \\
\hline i & $\begin{array}{l}\text { Strength }(1=\text { strong, } 0=\text { ambiguous, }-1=\text { weak }) \\
\text { Ambiguity }(-1=\text { unamb., }+2=\text { amb. }) \\
\text { SE }\end{array}$ & $\begin{array}{r}0.45 \\
-0.07 \\
0.03\end{array}$ & $\begin{array}{c}0.448 \\
-0.07 \\
0.03\end{array}$ \\
\hline 2 & $\begin{array}{l}\text { SE } \times \text { strength } \\
S E \times \text { ambiguity }\end{array}$ & $\begin{array}{l}-0.04 \\
-0.86\end{array}$ & $\begin{array}{l}-0.01 \\
-0.19\end{array}$ \\
\hline \multicolumn{4}{|c|}{ (c) Sad mood conditions } \\
\hline $\mathrm{i}$ & $\begin{array}{l}\text { Strength }(1=\text { strong, } 0=\text { ambiguous, }-1=\text { weak }) \\
\text { Ambiguity }(-1=\text { unamb., }+2=\text { amb. }) \\
\text { SE }\end{array}$ & $\begin{array}{r}0.13 \\
-0.12 \\
0.38\end{array}$ & $\begin{array}{c}0.13 \\
-0.12 \\
0.37 \dagger\end{array}$ \\
\hline 2 & $\begin{array}{l}\text { SE } \times \text { strength } \\
\text { SE } \times \text { ambiguity }\end{array}$ & $\begin{array}{r}-0.49 \\
0.96\end{array}$ & $\begin{array}{l}-0.13 \\
0.30 \ddagger\end{array}$ \\
\hline
\end{tabular}

*Each effect is adjusted for all effects entered in the same or preceding steps.

$\dagger p<0.01 ; \neq p<0.05 ; 5 p<0.001$.

should be biased by source evaluation for sad subjects who encounter ambiguous arguments, but not for happy subjects, and not for unambiguous arguments, regardless of recipient mood. This pattern was indeed obtained, as reflected in an interaction of mood, message ambiguity, and source evaluation $(r=-0.23, p<0.01$; see panel (a) of Table 3). Additional analyses within the sad mood condition revealed that sad subjects' attribute-related thoughts covaried with source evaluation $(r=0.37$, $p<0.005$; see panel (c) of Table 3), and that this correlation was stronger when the message was ambiguous than when it was unambiguous (interaction of source evaluation and ambiguity, $r=0.30, p<0.02$ ). Thus, we found evidence for a biasing effect of source perceptions on sad mood subjects' systematic processing of ambiguous messages. No effects of source evaluation on VAT were observed under happy mood $(p>0.12$ for all coefficients involving this predictor; see panel (b) of Table 3).

Predicting attitudes from reported mood: a test of the mood-as-cue hypothesis

To test whether mood influenced attitudes either directly or indirectly via moodcongruent thinking, two additional sets of regressions were performed, using attitudes 
and VAT scores, respectively, as the criterion. Predictors were message strength, ambiguity, reported mood, and their interactions.

For the full sample, these analyses yielded no significant results ${ }^{8}$ Additional analyses conducted separately for the two mood conditions also produced null effects. Thus, the present data give no indication that subjects etther used their mood as an heuristic cue or engaged in mood-congruent systematic processing.

\section{DISCUSSION}

Although the ANOVA yielded only weak evidence for mood effects on attitudes, the pattern of means and specific contrasts were nonetheless supportive of our prediction - and much past research - that people in sad moods are more influenced by variations in message content than are people in happy moods. We suspect that the failure to detect a reliable mood by argument quality effect in the overall ANOVA was due to the presence of a highly salient positive source cue in all experimental conditions. Indeed our specific predictions took this fact into account.

Despite the weak ANOVA results, the regression analyses substantiated mooddependent differences in processing strategies and the predictions of the HSM. Subjects in a sad mood, who processed systematically, also used heuristic cue information when message content was ambiguous. That both heuristic and systematic processing affected judgment in the sad-ambiguous condition provides further evidence that these modes need not be regarded as mutually exclusıve, antagonistic processing strategies. In combination with earlier findings (Bohner et al., 1992), the results suggest that the two strategies may co-occur when a recipient's negative affective state induces high motivation for processing and message content is ambiguous or insufficient.

Our study also provided support for the HSM's bias hypothesis. In a recent study by Chaiken and Maheswaran (in press), subjects' systematic processing of ambiguous message content was biased by evaluations of a source cue when task importance was high. Our data indicate that negative mood at the time of message processing may similarly enhance recipients' motivation to process and lead to analogous biasing effects of heuristic cues on systematic processing. To explore this possibility further, subsequent studies should feature explicit manıpulations of heuristic cues such as source credibility or consensus information.

The study provided little evidence for the use of mood itself as an heuristic cue or for mood-congruent systematic processing, even when message content was ambiguous. It should be acknowledged, however, that the direct, heuristic effects of mood may be restricted to circumstances in which motivation (or ability) for argument processing is low (Petty et al., 1993) and other heuristic cues are unavailable (Schwarz, 1990). Neither condition was met in the present experiment: the judgmental task was moderately involving (as evidenced by the high overall impact of message content), processing time was essentially unrestricted, and a salient 'competıng' heuristıc cue was present in all experimental conditions. It is less clear why mood-congruent systematic processing was not observed, given Petty et al.'s (1993) recent findings and our expectation that such processing would be especially likely with ambiguous

\footnotetext{
${ }^{8}$ Attitudes were independent of measured mood, $r=-0.02$; valenced attribute related thoughts showed a nonsignificant negative relation with mood, $r=-0.14$.
} 
message content. In line with ELM assumptions, perhaps the 'elaboration likelihood' was higher in the Petty et al. research than in our study Alternatively, and more speculatively, perhaps mood-congruent systematic processing is also restricted to circumstances in which salient heuristic cues are unavailable to recipients.

\section{Mood-persuasion research and other models of affect and cognition}

The results of recent research have dramatically changed our understanding of how mood influences persuasion, from the rather simplistic notion that happy people are easier to persuade (see McGuire, 1985) to a more complex, dual-process-oriented view (see Eagly and Chaiken, 1993; Schwarz et al., 1991). This research indicates that affective states influence people's information processing strategies and, hence, interact with factors such as argument quality and communicator variables to affect judgment.

How do these persuasion findings fit with other theorizing and research on the affect-cognition interface? In particular, why is it that evidence for mood-congruent judgment, a well-documented phenomenon in other judgment domains (e.g. Mayer, Gaschke, Braverman and Evans, 1992), has only rarely been observed by persuasion researchers (Petty et al., 1993)?

In other domains two major mechanisms have been proposed to account for moodcongruent judgment. According to the priming explanation, mood states automatically facilitate the retrieval of mood-congruent material from memory, which is then used as a basis of judgment (e.g. Bower, 1981, Isen, 1987). According to the mood-asinformation view, mood congruent judgment refiects people's tendency to use their mood states as informational cues, according to a 'How do I feel about it?' heuristic (Schwarz, 1990; Schwarz and Clore, 1988).

The priming mechanısm may be most likely to operate with self-referentıal and relatively unstructured material (see Blaney, 1986). In contrast, the messages that characterize persuasion research are usually well-structured and not typically selfreferential.

The mood-as-information mechanism can explain a range of mood-congruent judgment effects (see Schwarz, 1990). However, it is most likely to operate when (a) people have little reason to doubt the informational value of their feelings, and (b) affect is salient at the time the judgment is made. The ranty of mood main effects in persuasion studies might, then, be explicable to the extent that their mood inductions have been fairly obvious to subjects. Although possible, we suspect that the main reason for their rarity is that mood is typically induced prior to message exposure (but see Bless et al., 1992). Thus, it may exert its strongest impact on message encoding and elaboration, rather than at the subsequent judgment state ${ }^{9}$ As we have also noted, the heuristic nature of the mood-as-information effect implies that it should be most evident in low motivation settings.

To conclude, we note that the mood effects on processing strategy that persuasion researchers have documented appear to be a robust phenomenon. This is not to

\footnotetext{
'It is noteworthy that in one of the studies that obtained evidence for a direct effect of mood on attitude (Petty et al., 1993, Experiment 2), the persuasıve message was embedded in a television programme designed to induce positive (versus neutral) mood. Thus, the portion of the mood-inducing programme that subjects watched after the persuasive message may have amplified their current mood immediately before they were asked to make a judgment, renderıng mood-as-ınformation effects more likely.
} 
say that main effects of mood are unobservable in such research. However, the boundary conditions for the various mechanisms by which mood affects attitudes and other social judgments are not yet well understood (see Clore, Schwarz and Conway, in press; Forgas, 1992). Clarifying these hypotheses and their boundary conditions thus remains an important theoretıcal and empirical task.

\section{REFERENCES}

Blaney, P.H. (1986). 'Affect and memory: A review', Psychologıcal Bulletın, 99-229-246.

Bless, H., Bohner, G., Schwarz, N. and Strack, F. (1990). 'Mood and persuasion: A cognitive response analysis', Personality and Social Psychology Bulletin, 16: 331-345.

Bless, H., Mackie, D. M., and Schwarz, N. (1992). 'Mood effects on attutude judgments: The independent effects of mood before and after message elaboration', Journal of Personality and Social Psychology, 63: 885-895.

Bohner, G. (1990). 'Einflüsse der Stimmung auf die kognitıve Verarbeitung persuasiver Kommunikation und auf nachfolgendes Verhalten' [Mood influences on the processing of persuasive communication and on subsequent behavior]. Unpublished doctoral dissertation, Universität Heidelberg, Germany.

Bohner, G., Crow, K., Erb, H.-P. and Schwarz, N. (1992). "Mood effects on the processing of persuasive message content and context cues and on subsequent behavior', European Journal of Social Psychology, 2: 511-520.

Bower, G. (1981). 'Mood and memory', American Psychologist, 36: 129-148.

Chaiken, S. (1980). 'Heurıstic versus systematic information processing and the use of source versus message cues in persuasion', Journal of Personality and Social Psychology, 39, 752-766.

Chaiken, S. (1987). 'The heuristic model of persuasion'. In: Zanna, M. P., Olson, J. M and Herman, C. P. (Eds) Social Influence: The Ontarıo Symposium, Vol. 5, Erlbaum, Hillsdale, N.J., pp. 3-39.

Chaiken, S., Liberman, A. and Eagly, A. H. (1989). 'Heuristic and systematıc information processing within and beyond the persuasion context'. In: Uleman, J. S. and Bargh, J. A. (Eds) Unintended Thought Guilford, New York, pp. 212-252.

Chaiken, S. and Maheswaran, D. (in press). 'Heurıstic processing can bias systematic processing: Effects of source credibility, argument ambıgutty, and task importance on attitude judgment'. Journal of Personality and Social Psychology

Clore, G. L., Schwarz, N. and Conway, M. (in press). 'Affective causes and consequences of social information processing'. In: Wyer, R. S. and Srull, T. K. (Eds) Handbook of Social Cognition, 2nd edn., Erlbaum, Hillsdale, NJ.

Eagly, A. H. and Chaiken, S. (1993). The Psychology of Alttudes, Harcourt Brace Jovanovich, Fort Worth, TX.

Fiedler, K. (1988). 'Emotional mood, cognitive style, and behavior regulation' In: Fiedler, K. and Forgas, J. (Eds) Affect, Cognition and Soctal Behavior, Hogrefe, Toronto, pp. 100119.

Forgas, J. P. (1992). 'Affect in social judgments and decisions: A mult1-process model' In: Zanna, M. P. (Ed.) Advances in Experimental Social Psychology, Vol. 25, Academic Press, San Diego.

Frijda, N. H. (1988). 'The Laws of Emotion', American Psychologist, 43: 349-358.

Innes, J. M. and Ahrens, C. R. (1991). 'Positive mood, processing goals and the effects of information on evaluative judgment'. In: Forgas, J. (Ed.) Emotion and Soctal Judgments, Pergamon, Oxford.

Isen, A. M. (1987). 'Positive affect, cognitive processes, and social behavior' In: Berkowitz, L. (Ed.) Advances in Experimental Social Psychology, Vol. 20, Academic Press, San Diego, pp. 203-253.

Mackie, D. M. and Worth, L. T. (1989). 'Processing deficits and the mediation of positive affect in persuasion', Journal of Personality and Social Psychology, 57: 27-40.

Mayer, J. D., Gaschke, Y N., Braverman, D. L. and Evans, T. D. (1992). 'Mood-congruent judgment is a general effect', Journal of Personality and Soctal Psychology, 63: 119-132. 
McGuire, W J. (1985). 'Attitudes and attitude change' In: Lindzey, G. and Aronson, E. (Eds) Handbook of Social Psychology, 3rd edn, Vol. 2, Random House, New York.

Petty, R. E. and Cacioppo, J. T (1981). Attitudes and Persuasion: Classic and Contemporary Approaches, Brown, Dubuque, IA.

Petty, R. E. and Cacioppo, J. T (1986). Communtcation and Persuasion. Central and Peripheral Routes to Attitude Change, Springer, New York.

Petty, R. E., Cacioppo, J. T and Kasmer, J. A. (1988). 'The role of affect in the elaboration likelihood model of persuasion' In: Donohue, L., Sypher, H. E. and Higgins, E. T (Eds) Communication, Social Cognition, and Affect, Eribaum, Hillsdale, N.J., pp. 117-146.

Petty, R. E., Schumann, D. W., Richman, S. A. and Strathman, A. J. (1993). 'Positive mood and persuasion: Different roles for affect under high and low elaboration conditions', Journal of Personality and Social Psychology 64: 5-20.

Schwarz, N. (1990). 'Feelings as information: Informational and motivational functions of affective states' In: Higgins, E. T and Sorrentıno, R. (Eds) Handbook of Motivation and Cognition: Foundations of Soctal Behavior, Vol. 2, Guilford, New York, pp. 527-561.

Schwarz, N., Bless, H. and Bohner, G. (1991). 'Mood and persuasion: Affective states influence the processing of persuasive communications' In: Zanna, M. (Ed.) Advances in Experimental Social Psychology, Vol. 24, Academic Press, New York, pp. 161-199.

Schwarz, N. and Clore, G. L. (1988). 'How do I feel about it? The informative function of affectıve states' In: Fiedler, K. and Forgas, J. (Eds) Affect, Cognition, and Social Behavior, Hogrefe International, Toronto, pp. 44-62.

Worth, L. T. and Mackie, D. M. (1987). 'Cognitive mediation of positive affect in persuasion', Social Cognition, 5: 76-94. 